\title{
Chronic cor pulmonale in pulmonary sarcoidosis
}

\author{
J. P. BATTESTI, R. GEORGES, F. BASSET, AND G. SAUMON
}

From CHU Bobigny_Paris 13, Service de Pneumologie and INSERM, Groupe de Recherches U 82, Paris, France

Battesti, J. P., Georges, R., Basset, F., and Saumon, G. (1978). Thorax, 33, 76-84. Chronic cor pulmonale in pulmonary sarcoidosis. Right-heart overload happens relatively rarely in sarcoidosis, even with fibroemphysematous changes. Of 21 cases that we studied, six $(28 \%)$ had clinical and/or electrocardiographic features of cor pulmonale. The cause of cor pulmonale often evoked is an invasion of the walls of pulmonary vessels by sarcoid granulomas or their compression by the fibrotic process. Pathological studies in one patient showed compression of large pulmonary arteries associated with specific sarcoid lesions in small and medium-sized arteries.

The development of chronic cor pulmonale due to pulmonary hypertension has rarely been described in pulmonary sarcoidosis, even in chronic fibroemphysematous forms. The mechanisms often evoked to explain the occurrence of pulmonary hypertension are based on histological findings, the perivascular occurrence of granulomas with the fibrosis which sometimes results, and the possibility of thrombosis or invasion of arterial and vein walls by granulomas.

\section{Material and methods}

Twenty-one cases of chronic sarcoidosis were studied.

The diagnosis was made using clinical, radiological, pathological (bronchial biopsy), and immunological (Kveim test, tuberculin anergy) findings. Such a diagnosis was confirmed in life by these methods even in the two cases ( 2 and 5) where no definite evidence of sarcoidosis was found at necropsy many years later.

The radiographic classification was based on postero-anterior and lateral views, occasionally confirmed by tomography.

Evidence of right-sided heart involvement was based upon clinical examination and six electrocardiographic criteria (Schaub, 1966):

1 QRS vector angle in the frontal plane (angle $\alpha$ ) $\geqslant+90^{\circ}$.

2 Negative $T$ wave in $S_{2}$ and $S_{3}$ or $S_{3}$ and $\alpha \geqslant+90^{\circ}$

$3 \mathrm{~S}$ wave in $\mathrm{V}_{5}$ and $\mathrm{V}_{6} \geqslant 0.7 \mathrm{mV}$.

$4 R$ wave in $V_{1}+S$ wave in $V_{5}>1 \mathrm{mV}$.
5 QRS direction to the right and posterior: $\mathrm{rS}$ of $\mathrm{V}_{1}$ to $\mathrm{V}_{4}$, sometimes $\mathrm{rS}$ or Qs of $\mathrm{V}_{1}$ to $V_{6}$ with positive or flattened $T$ waves.

6 Incomplete right bundle-branch block: $\mathrm{rSS}_{\overline{\mathrm{S}}}$ $R^{\prime}$ in $V_{1}$ with $R^{\prime}$ in $V_{1} \geqslant 10 \mathrm{mV}$.

Radiological measurement of the size of the righto heart chambers and the diameter of the pulmonary arteries was in most cases impossible because of $\overrightarrow{0}$ the perihilar pulmonary opacities which obscured ${ }^{3}$ the cardiac and arterial contours. Thus radio logical criteria were not taken into account.

\section{Results}

ANALYSIS OF THE 21 CASES
The main results are shown in the Table. Three radiological groups may be distinguished:

Type I (5 cases) Very dense perihilar 'pseudotumour' shadows (with or without cavities); retrac-응 tion of the upper lobes and transradiancy without 7 bullous formation of the lower lobes (Fig. 1)

Type II (11 cases) Diffuse reticulonodulation. N Two subgroups can be formed:

IIa (6 cases) Reticulation of either micro- $N$ nodular or honeycomb types evenly distributedw throughout both lungs (Fig. 2).

IIb (5 cases) Irregular pulmonary reticulationo with dense linear opacities scattered throughout the lungs.

Type III (5 cases) Thin-walled transradiancies and dense linear opacities, suggesting bullous

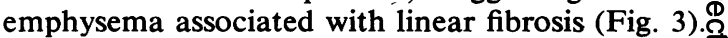

In all patients, the radiographic abnormalitiesक remained unchanged for several years in spite of 
Table Radiographic and cardiac features

\begin{tabular}{lllll}
\hline Case & $\begin{array}{l}\text { Radiologi- } \\
\text { calgroup }\end{array}$ & $\begin{array}{l}\text { Frontal } \\
\text { QRS } \\
\text { vector } \\
(a)\end{array}$ & $\begin{array}{l}\text { Electrocardiographic } \\
\text { criteria }\end{array}$ & $\begin{array}{l}\text { Clinical } \\
\text { right } \\
\text { heart } \\
\text { failure }\end{array}$ \\
\hline 1 & I & +90 & $\mathrm{C} 2$ & + \\
2 & I & +60 & & \\
3 & I & +30 & & + \\
4 & I & +30 & & \\
5 & I & +160 & $\mathrm{C} 1+\mathrm{C} 2+\mathrm{C} 3+\mathrm{C} 4+\mathrm{C} 6$ & + \\
6 & IIa & +70 & & \\
7 & IIa & -80 & $\mathrm{C} 1+\mathrm{C} 2+\mathrm{C} 3+\mathrm{C} 4+\mathrm{C} 5$ & + \\
8 & IIa & +20 & & \\
9 & IIa & +120 & $\mathrm{C} 1+\mathrm{C} 2+\mathrm{C} 3+\mathrm{C} 4+\mathrm{C} 6$ & + \\
10 & IIa & +10 & & \\
11 & IIa & +90 & $\mathrm{C} 2+\mathrm{C} 3$ & \\
12 & IIb & +30 & & \\
13 & IIb & 0 & & \\
14 & IIb & +120 & $\mathrm{C} 1$ & \\
15 & IIb & & & \\
16 & IIb & +30 & & \\
17 & III & -30 & & \\
18 & III & +60 & & \\
19 & III & +30 & & \\
20 & III & +60 & & \\
21 & III & +30 & & \\
\hline & & & & \\
\hline
\end{tabular}

prolonged corticosteroid therapy. Clinical rightsided heart failure was observed in four cases and electrocardiographic patterns suggestive of cor pulmonale were noted in six cases. All cases with clinical right heart failure showed electrocardiographic abnormalities, usually with the association of several criteria. Electrocardiographic changes were observed in radiological groups I and IIa 5 times out of 11 .

ANALYSIS OF CASE 7

A 49-year-old white woman was admitted to hospital in January 1975. She had isolated pulmonary sarcoidosis with dyspnoea on exertion and a bilateral diffuse nodulo-infiltrative appearance on chest radiography with a massive lingular infiltrate; the diagnosis was made by bronchial biopsy and immunological findings. The electrocardiogram showed signs of cor pulmonale (Table). Worsening of her dyspnoea and the rapid onset of clinical heart failure suggested pulmonary embolism. Angiography (Fig. 4) through a venous catheter revealed complete obstruction of the left upper lobe artery and stenosis with secondary recanalisation of the right lower and upper lobe arteries. Death occurred in March 1975.

Necropsy showed numerous calcified paratracheal and interbronchial nodes, which compressed the proximal pulmonary arteries (Fig. 5). The lungs showed fibrotic areas in the upper lobes and a subpleural infarct in the right lower lobe.

Several types of lesion were observed in histological sections. There was severe congestion, the alveolar exudates showing oedema, haemorrhage, and macrophages. On this background two types of focal lesions stood out. The first consisted of

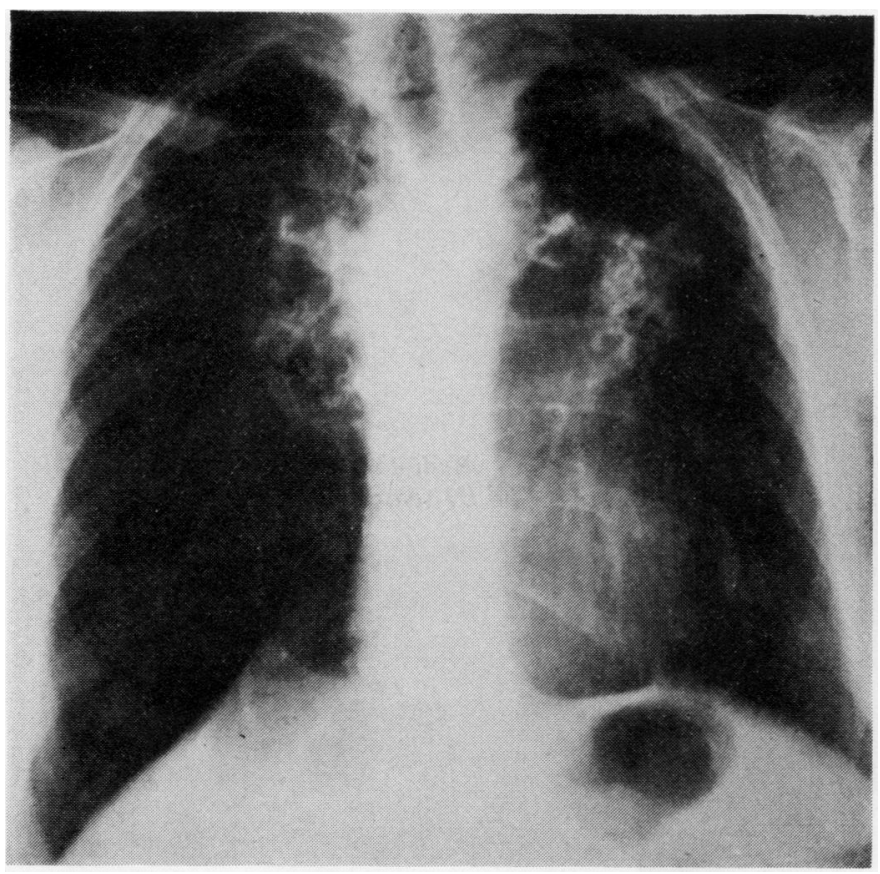

Fig. 1 Radiological picture characteristic of type I (case 2). 


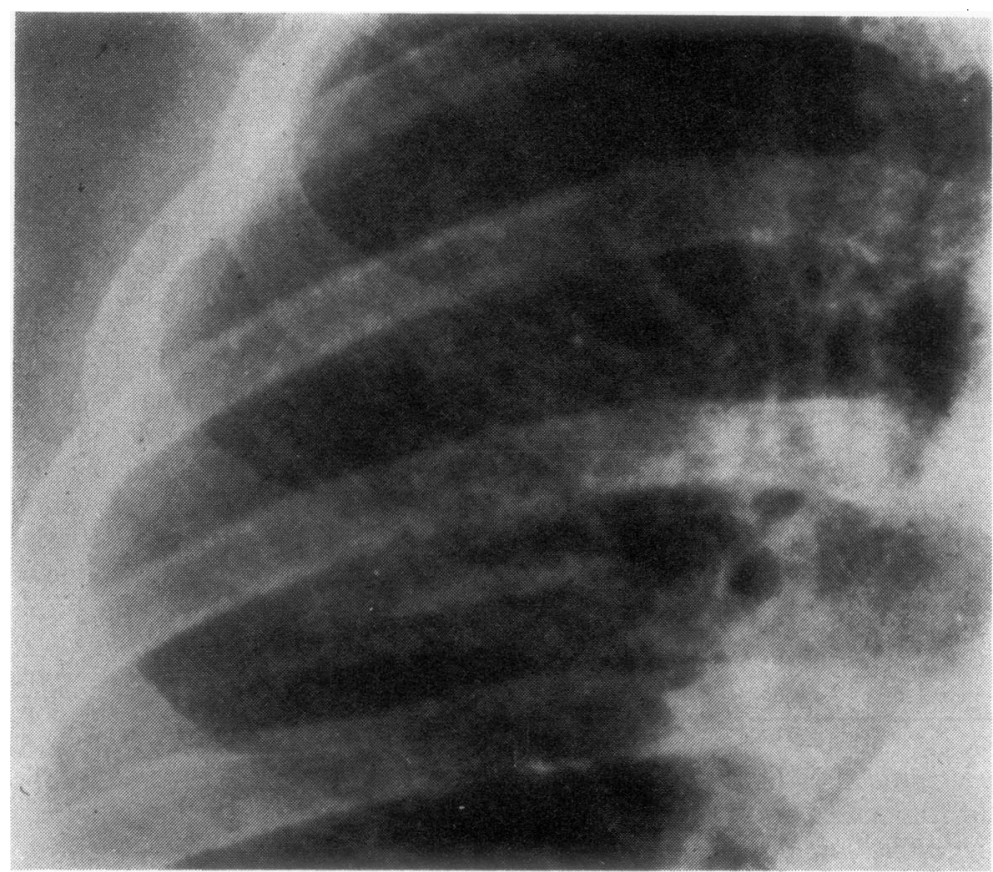

Fig. 2 Radiological picture characteristic of type II: enlarged detail of diffuse reticulomicronodular infiltrates (case 9).

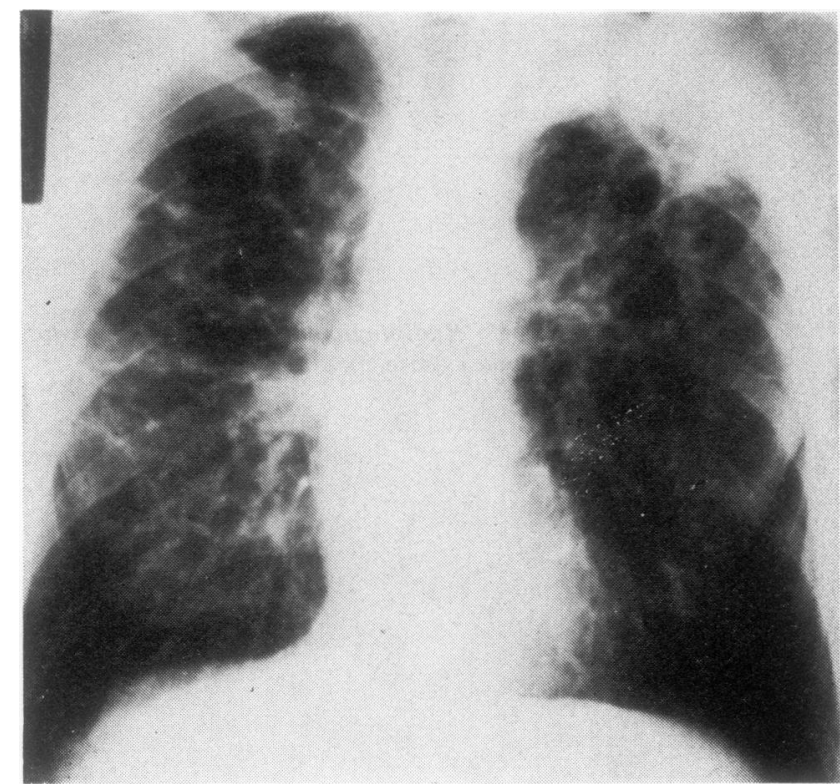

Fig. 3 Radiological picture characteristic of type III (case 19). 


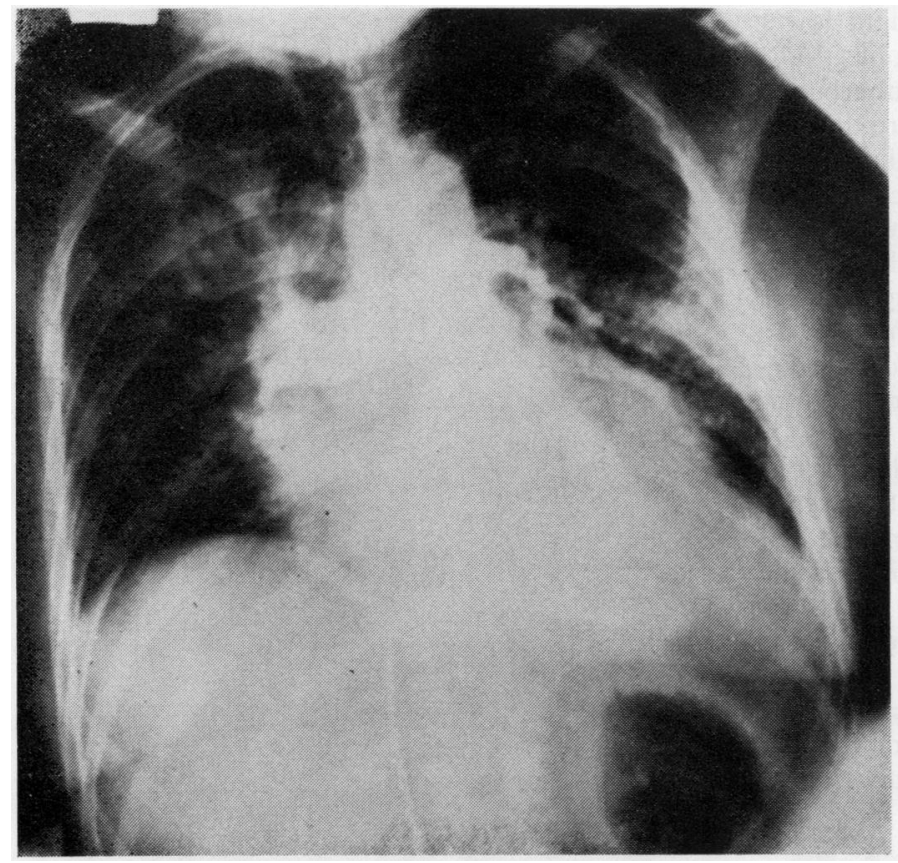

Fig. 4 Pulmonary arteriogram (posteroanterior view) showing obstruction of pulmonary vessels (case 7).

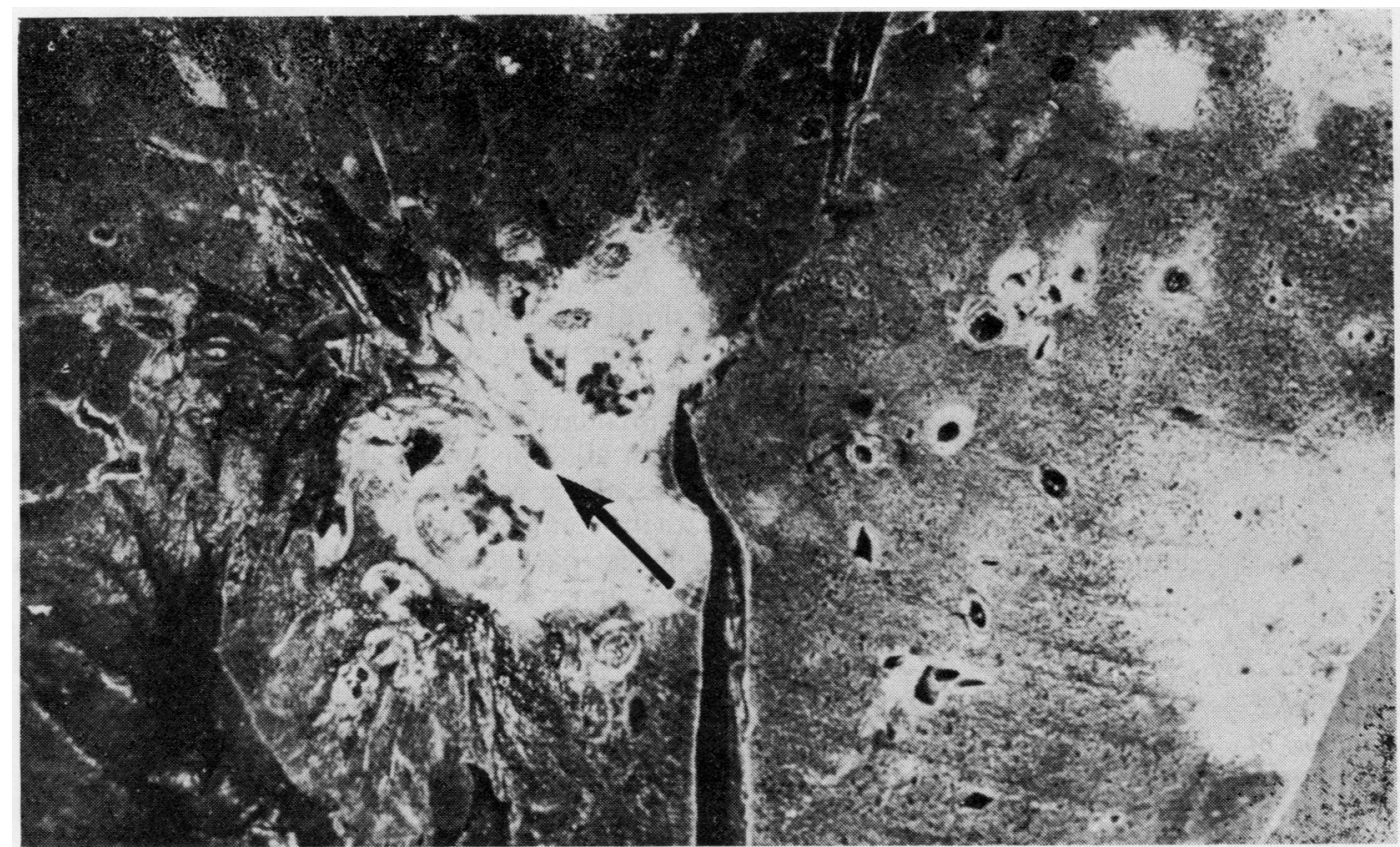

Fig. 5 Gross section of left lung showing white fibrotic areas with tiny arterial lumina, one of which (arrow) is especially narrowed. 
infarcts, not only the large one in the right lower lobe, but also smaller, more recent ones. The other type of lesion consisted of tuberculoid granulomas without necrosis. They were usually found along the bronchovascular sheaths, invading the bronchial and, to a lesser degree, the vascular walls. They were also numerous at the edges of large fibrotic areas, apparently in pulmonary tissue. However, their proximity to large bronchi and vessels and the presence of a hyalinised border and central anthracotic pigmentation led us to interpret these fibrous areas as hyalinised lymph nodes.

In the walls of large bronchi, follicular lesions at every stage, without any signs of caseous necrosis, were associated with shrinkage of adjoining bronchial lumina with disruption of the bronchial cartilage.

Most vessels exhibited important changes. Their walls were thickened by fibrosis, either loose and cellular, or compact (Fig. 6). The lumen was narrow when present, or was replaced by tiny recanalisation channels (Fig. 7). Embedded in the

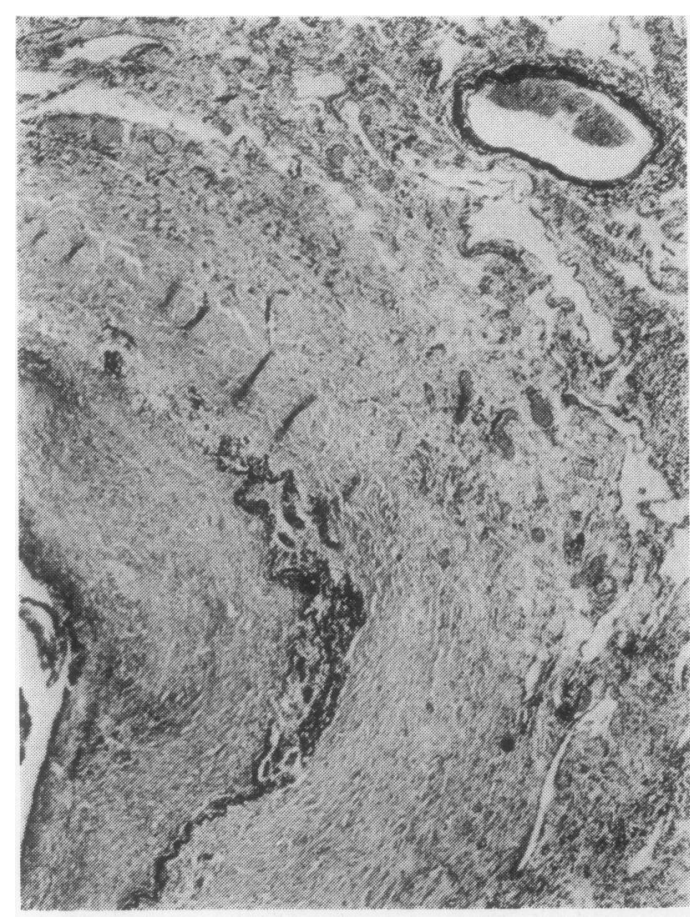

Fig. 6 Part of a large pulmonary artery: the narrow lumen is visible on the left of the picture, with a partially occluding thrombus. The arterial wall is fibrous and thickened, and the black-stained elastic lamina is disrupted by cell aggregates with giant cells (Verhoeff's stain $\times 15)$.

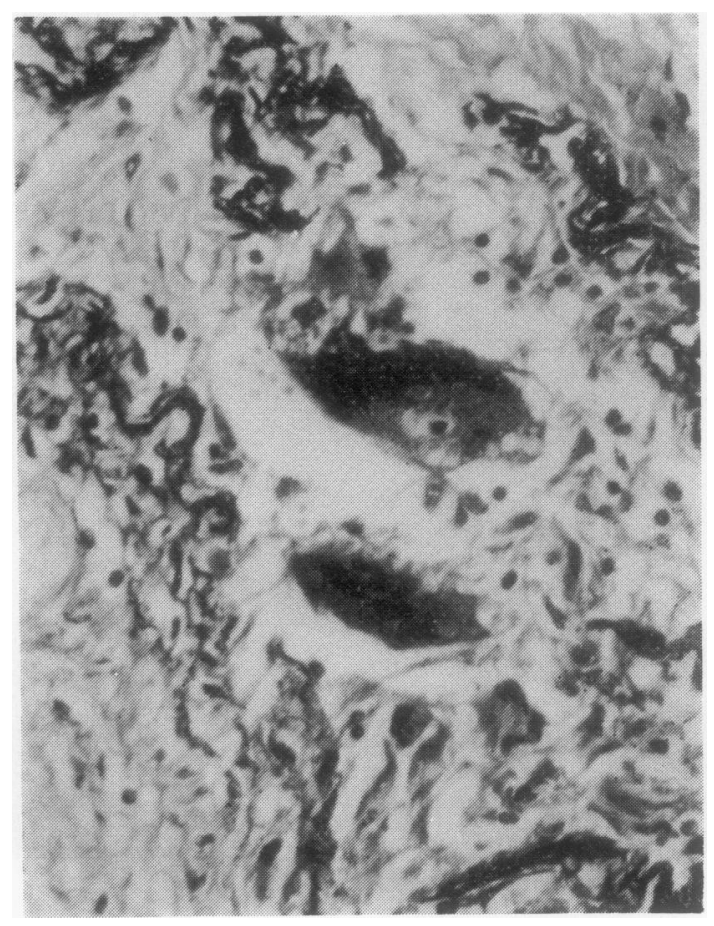

Fig. 7 Higher magnification of Fig. 6, showing recanalisation $(\times 295)$.

wall, follicular lesions sometimes disrupted the elastic laminae (Figs 8 to 10).

In larger arteries, there were thrombi of varying age and size adhering to the wall (Fig. 6). In 은 small arteries, lesions were plexiform with several $\stackrel{0}{x}$ narrow lumina and a disorganised smooth muscle 0 layer (Figs 11 and 12).

Mediastinal lymph nodes had an appearance $ᄋ$ similar to that of the hyalinised masses attached to lung tissue, which was an additional reason for음 interpreting the latter as lymph nodes fused to $\square$ pulmonary tissue.

In addition to the above vascular lesions, there was also a reduction in size of the arteries due to their compression by the hyalinised hilar lymph ${ }_{0}$ nodes (particularly the left main pulmonary and ${ }_{\omega}^{N}$ the upper left lobe arteries). This vascular compression was further increased by the contracturato fibrosis of all this region, causing bronchial $\frac{\mathbb{}}{\widetilde{D}}$ distortion and the blending of lymph nodes into $\stackrel{\oplus}{+}$ neighbouring pulmonary tissue.

\section{Discussion}

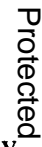

Clinical manifestations of cor pulmonale are rarely reported in fixed fibro-emphysematous forms of 


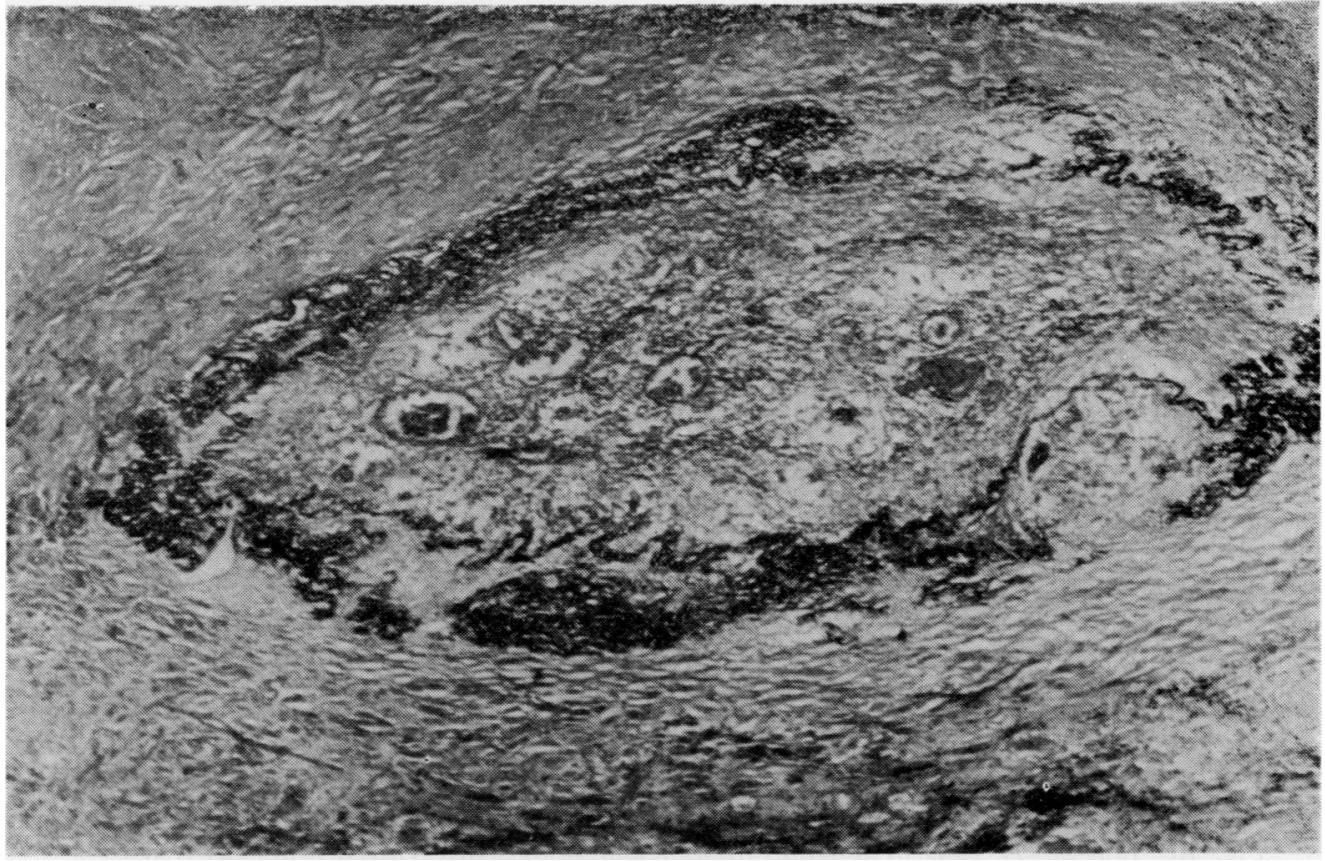

Fig. 8 Close to a hyalinised area, an arterial lesion with intimal fibrosis and a few recanalisation vessels. Several epithelioid and giant-cell granulomas disrupt or distort the elastic lamina $($ Verhoeff's stain $\times 40)$.

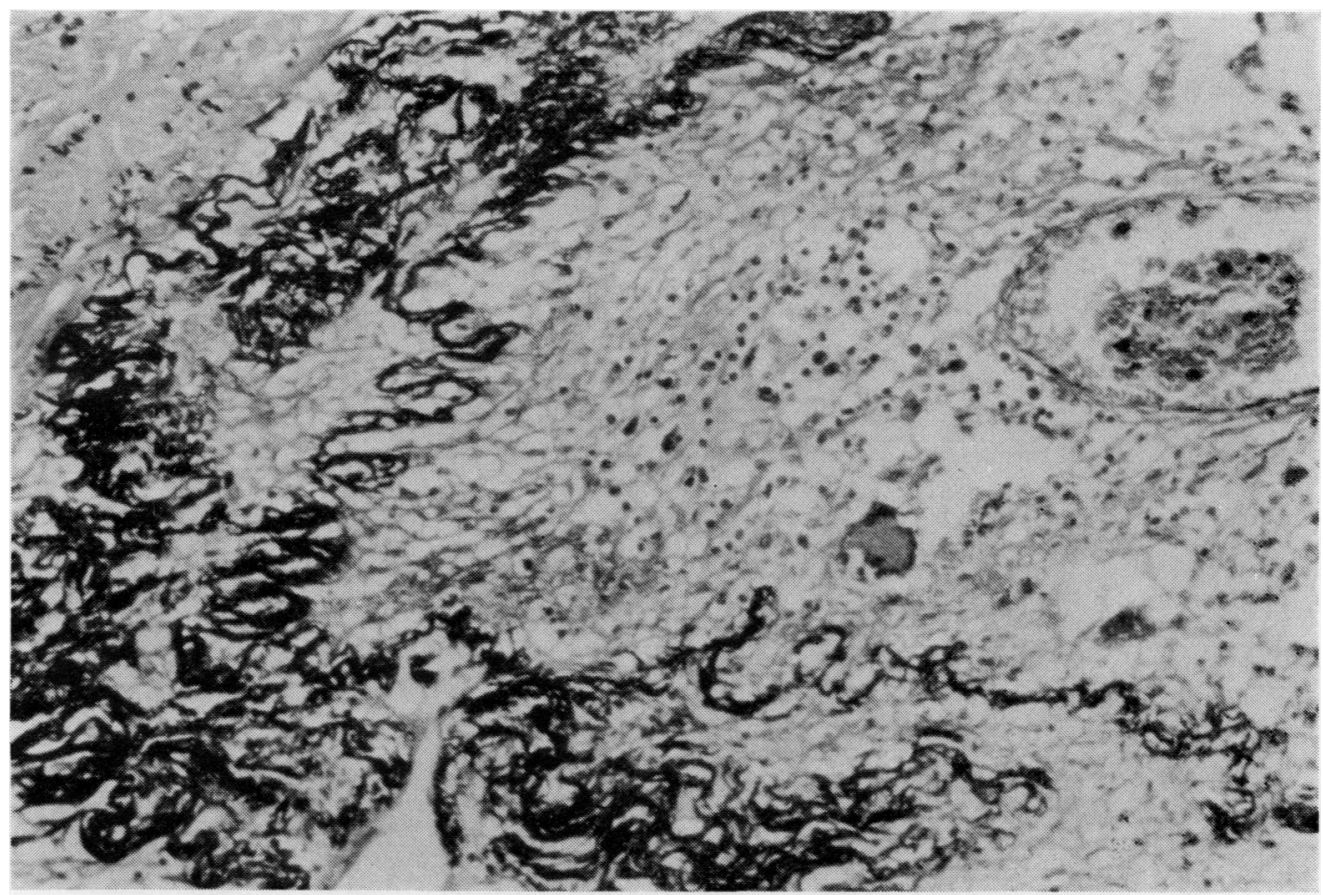

Fig. 9 Higher magnification of Fig. 8, showing loose cellular infiltrates, giant cells, and changes in the elastic lamina $(\times 165)$. 


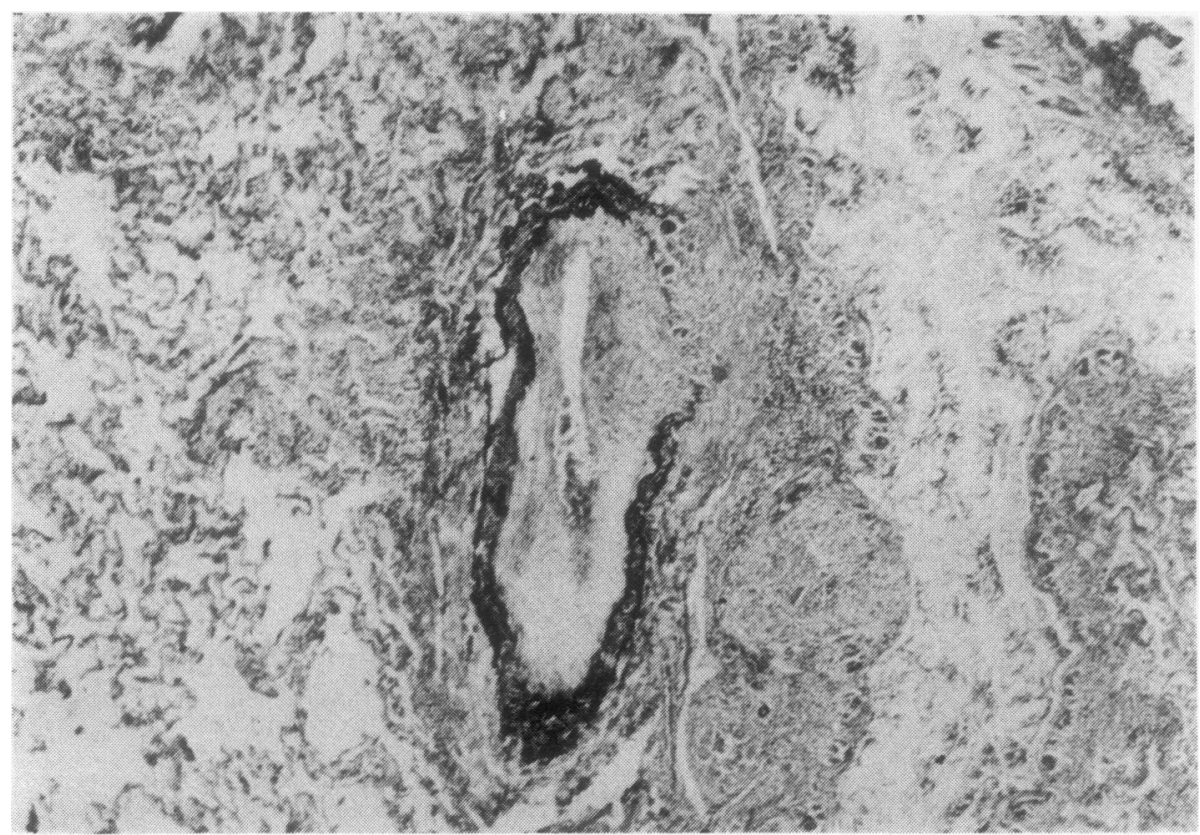

Fig. 10 Low-power view of a group of follicular lesions involving a bronchus (cut lengthwise, on the right side of the picture) and a narrow artery with a disrupted elastic lamina (Verhoeff's stain $\times 16 \cdot 5)$.

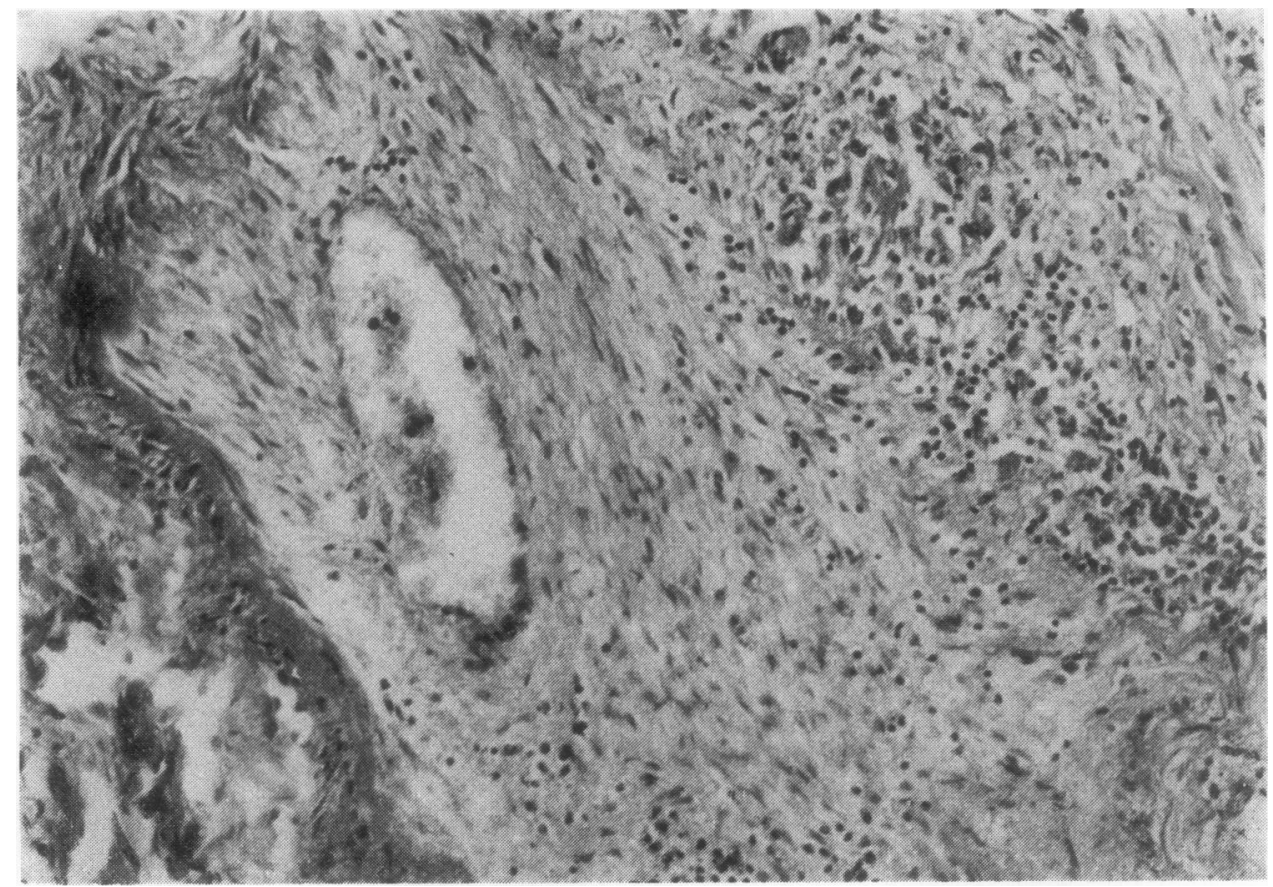

Fig. 11 Obliquely cut vessel, the wall of which is in close contact with a granuloma (Haematoxylin and eosin $\times 135$ ). 


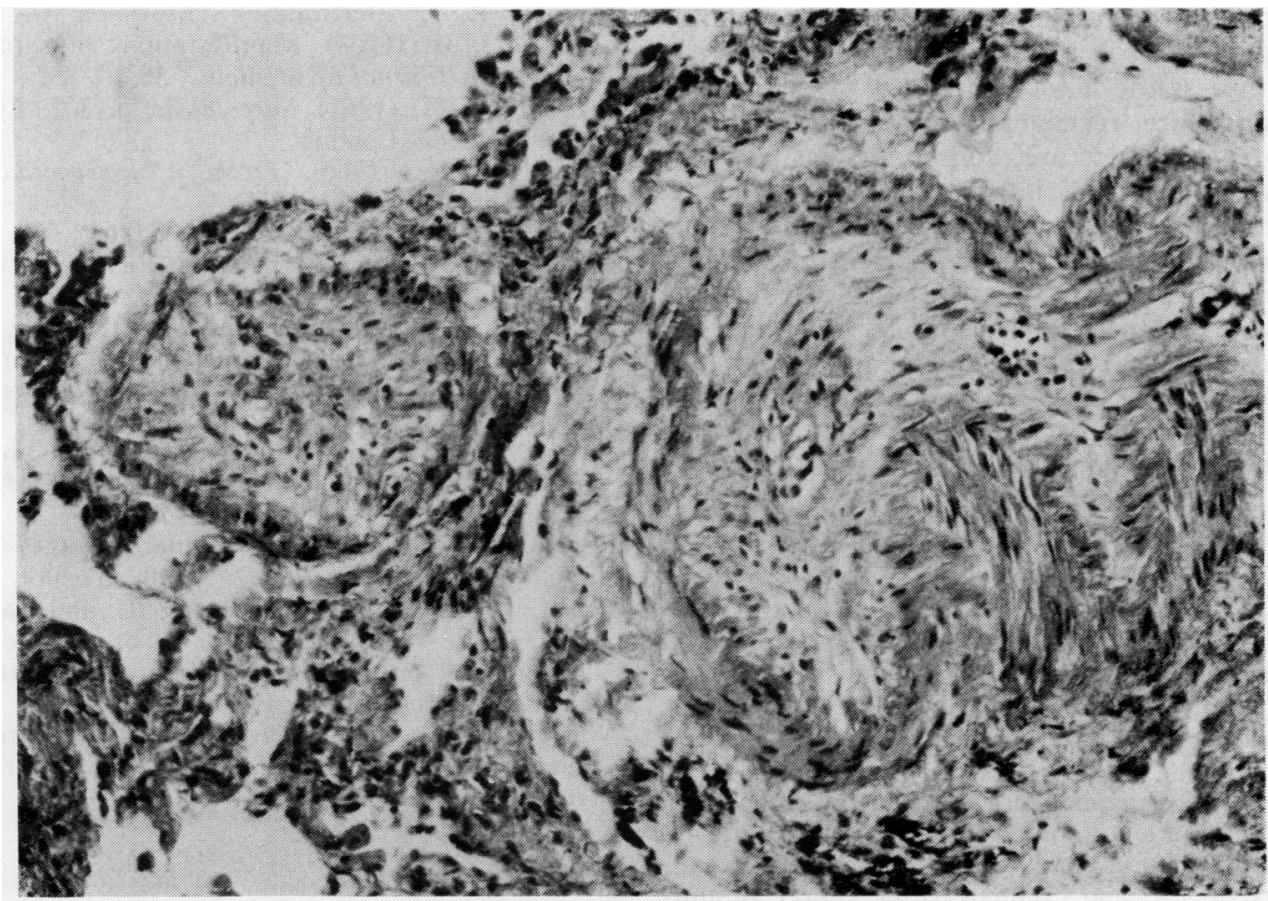

Fig. 12 Plexiform lesion (Haematoxylin and eosin $\times 135$ ).

pulmonary sarcoidosis. Among 13 patients who died from sarcoid pulmonary fibrosis, Scadding (1967) observed three with clinical right ventricular failure and one with isolated electrocardiographic right ventricular hypertrophy, thus finding evidence of chronic cor pulmonale in $30 \%$ of cases. According to this author, the association with chronic bronchitis is an important aetiological factor. Out of 11 necropsies of sarcoid fibrosis, Sones and Israel (1960) observed four cases of chronic cor pulmonale $(36 \%)$; Mayock et al. (1963) noted three cases out of nine deaths. In our group, chronic cor pulmonale manifestations with or without right heart failure were observed in six out of 21 cases $(28.6 \%)$.

Studies of the pathology of pulmonary hypertension in sarcoidosis have shown in the majority of cases only the small and medium-sized arteries to be clearly affected. Lesions consist of generally incomplete thrombosis provoked by either peribronchovascular fibrosis or granulomatous invasion of the vascular walls (Mallory, 1948; Longcope and Freiman, 1952; Thompson, 1966; Turiaf et al., 1973). Thromboembolism may be superimposed in some cases. On the other hand, involvement of the large branches of the pulmonary artery is exceptional. Schermuly and Behrend (1968) performed pulmonary angiography on 150 subjects suffering from sarcoidosis and observed modifications in the orientation of the proximal arteries. These modifications were attributed to the fibrosis, but no change in size of the pulmonary vessels provoked by lymph-node compression was noted. The authors did not specify the stage of evolution of the illness (in particular, the presence or absence of mediastinal adenopathies).

Shibel et al. (1969) studied 31 subjects suffering from sarcoidosis and noticed abnormalities in peripheral perfusion detected by scintigraphy in two cases where isolated mediastinal adenopathy was present. The authors postulated either the existence of pulmonary impairment undetected by radiography or a decrease in the diameter of the proximal vessels. Westcott and de Graff (1973) reported the case of a 29-year-old coloured man with mediastinal lymph adenopathy. Scintigraphy revealed a perfusion defect of the upper right lobe, suggesting pulmonary embolism. A right pulmonary arteriogram showed compression of the right upper lobe artery by hilar nodes. Eleven months later, the chest radiograph and scintigraphy spontaneously returned to normal. Gordonson et al. (1973) reported a case of compression by an enlarged right paratracheal node of the superior vena cava. This was completely 
asymptomatic and diagnosed by venacavagram.

Enlarged sarcoid mediastinal lymph nodes can thus compress the large pulmonary vessels. When such nodes are recent and have an essentially granulomatous structure, compression is certainly very exceptional and, in any case, reversible. At the fibroemphysematous stage, when the enlarged nodes have undergone fibrohyaline transformation and are sometimes the site of calcification, irreversible compression of the large pulmonary vessels can be more easily explained. Its frequency is difficult to assess in the absence of angiographic information. In our case 7 , the role of lymph nodes in compression and obstruction of the large vessels is particularly evident, but the presence of sarcoid lesions in vascular walls appears to occur also throughout the whole vascular tree.

We are grateful to Mrs. Mazin and Miss Jarland for their skilful technical assistance.

\section{References}

Gordonson, J., Trachtenberg, S., and Sargent, E. N. (1973). Superior vena cava obstruction due to sarcoidosis. Chest, 63, 292-293.

Longcope, W. T., and Freiman, D. G. (1952). A study of sarcoidosis. Medicine, 31, 1-32.

Mallory, T. B. (1948). Pathology of pulmonary fibrosis including chronic pulmonary sarcoidosis. Radiology, 51, 468-476.
Mayock, R. L., Bertrand, P., Morisson, C. E., and Scott, J. H. (1963). Manifestations of sarcoidosis. American Journal of Medicine, 35, 67-89.

Scadding, J. G. (1967). Sarcoidosis, p. 302. Eyre and Spottiswoode, London.

Schaub, F. A. (1966). Précis d'Électrocardiographie Clinique. J. R. Geigy. Bâle.

Schermuly, W., and Behrend, H. (1968). Die Angio- $\overrightarrow{0}$ graphie der Lungensarkoidose. Radiologe, 8, 116123.

Shibel, E. M., Tisi, G. M., and Moser, K. M. (1969). Pulmonary photoscan roentgenographic comparisons in sarcoidosis. American Journal of Roentgenology, 106, 770-777.

Sones, M., and Isracl, H. L. (1960). Course and prognosis of sarcoidosis. American Journal of Medicine, $\sigma$ 29, 84-93.

Thompson, J. R. (1966). Vascular changes in sarcoidosis. Diseases of the Chest, 50, 357-361.

Turiaf, J., Battesti, J. P., Georges, R., and Basset, F. 믈 (1973). Le stade III ou stade de fibrose de la sarcoïdose pulmonaire. Revue Française des Maladies Respiratoires, 1, 1089-1108.

Westcott, J. L., and de Graff, C. (1973). Sarcoidosis $\vec{\theta}$ hilar adenopathy and pulmonary artery narrowing. Radiology, 108, 585-586.

Requests for reprints to: Professor J. P. Battesti, Service de Pneumologie, Hôpital Franco-Musulman, 125 rue de Stalingrad, F 93009 Bobigny, France. 
function are presented in the table. The patient was restudied four months later, and the results with analgesics were very much the same.

\section{Comment}

Airways obstruction was strikingly relieved by aspirin in the patient studied. Similar beneficial effects were produced by three other cyclooxygenase inhibitors, that is, by indomethacin, mefenamate, and fenoprofen, but not by two remaining analgesics-salicylamide and benzydamine-which do not inhibit PG biosynthesis (Vane, 1976; Szczeklik et al, 1977). It was, therefore, logical to assume that the pharmacological removal of a product of arachidonic acid (AA) cyclooxygenation from his respiratory tract helped our patient to overcome the airways obstruction. Perhaps this product was a bronchoconstrictor $\mathrm{PGF}_{2} \alpha$, $\mathrm{TXA}_{2}$, or other as yet unknown metabolite. Whatever the metabolite was, it could not have been a physiological one, since we have found that bronchodilator $\mathrm{PGI}_{2}$ and $\mathrm{PGE}_{2}$ are two major products of AA transformation in the lungs (Gryglewski et al, 1978).

In our patient the suspected abnormality in arachidonate metabolism was restricted to the respiratory system. Detailed platelet function studies, particularly those related to arachidonic pathway, failed to show any differences from the normal. The transient petechiae were most likely due to increased vascular fragility secondary to triamcinolone administration.

The number of asthmatic patients who might benefit from aspirin is not known. Trial of aspirin treatment might seem warranted in asthma, since it could allow the steroid dose to be reduced, as in our case. Great care, however, would be necessary at the beginning of such treatment, and the initial dose of aspirin should not exceed $20-40 \mathrm{mg}$, as the same cyclo-oxygenase inhibitors, which proved to be so efficient in relieving bronchoconstriction in our patient, may produce bronchoconstriction in other asthmatics suffering from socalled aspirin-induced asthma (Szczeklik et al, $1975 ; 1977)$. Thus two opposite reactions can be caused in asthmatics by the same specific inhibitors. This indicates that different mediators, even derived from the same precursor, might play a different role in various types of asthma.

\section{Discussion}

Gryglewski, R J, Korbut, R, Ocetkiewicz, A (1978). Generation of prostacyclin by lungs in vivo and its release into arterial circulation. Nature, 273, 765767.

Szczeklik, A, Gryglewski, R J, and CzerniawskaMysik, G (1975). Relationship of inhibition of prostaglandin biosynthesis by analgesics to asthma attacks in aspirin-sensitive patients. British Medical Journal, 1, 67-69.

Szczeklik, A, Gryglewski, R J, and CzerniawskaMysik, G (1977). Clinical patterns of hypersensitivity to nonsteroidal anti-inflammatory drugs and their pathogenesis. Journal of Allergy and Clinical Immunology, 60, 276-284.

Szczeklik, A, Gryglewski, R J, Musial, J, Grodzińska, L, Serwońska, M, and Marcinkiewicz, E (1978). Thromboxane generation and platelet aggregation in survivals of myocardial infarction. Thrombosis and Haemostasis. (In press.)

Vane, J R (1976). The mode of action of aspirin and similar compounds. Journal of Allergy and Clinical Immunology, 58, 691-704.

Requests for reprints to: Dr A Szczeklik, Copernicus Academy of Medicine, Skawińska 8, 31-066 Cracow, Poland.

\section{Corrections}

1 Warren, C P W et al. Mechanical properties of the lung in extrinsic allergic alveolitis. Thorax, 1978, 33, 315-321.

The caption to figure 1 should show (a) four weeks and (b) one week.

2 Battesti, V P et al. Chronic cor pulmonale in pulmonary sarcoidosis. Thorax, 1978, 33, 76-84.

The authors regret that they omitted to acknowledge Professor J Turiaf, who originally studied the patients. 